towards socially constructive goals (such as better health or nutrition). He concludes with some general proposals. He would like to democratize procedures within the scientific community so that priorities and practices would be open for broader public discussion; he would like to change the research funds to allow greater public input; he wants to develop ways of democratizing technological innovation to ensure that considerations of equity influence production; and he wants to publicly funded research.

Dickson ends his book on a bizarre note, by taking encouragement from the effectiveness of the Creationists in challenging scientific ideas. In my view, he misinterprets the significance of institutions responsible for allocating maintain public access to the fruits of

Creationism. Far from creating a "political program that includes a vision of an alternative science', this group has manipulated the populist tendencies of American Fundamentalists to enhance the power of a small religious group. Yet this conclusion to the book should not divert the reader from its very positive, indeed Utopian message - that science, one of the greatest cultural and intellectual achievements of the modern age, must be shaped in accordance with democratic values in order to enhance the public good.

Dorothy Nelkin is a Professor in the Cornell University Program on Science, Technology and Society, and a Visiting Scholar at the Russell Sage Foundation, New York. She is author of Science as Intellectual Property (Macmillan, 1984), and with Michael S. Brown, of Workers at Risk (University of Chicago Press, 1984).

\section{Metallic electrons}

\section{Michael Springford}

Magnetic Oscillations in Metals.

By D. Shoenberg.

Cambridge University Press: 1984.

Pp.570. £55, \$97.50.

OCCASICNAI.LY a book appears of which it may be said that the author, the content and the timing could not be bettered. Magnetic Oscillations in Metals by Professor David Shoenberg is just such a book.

It was in 1932, at the suggestion of Kapitza, that the author, then a new graduate student at the Royal Society Mond Laboratory in Cambridge, was introduced to the mysterious magnetic properties of bismuth. Only a few years previously, in Leiden, de Haas and van Alphen had observed magnetic oscillations in this metal at low temperatures. The oscillations of the magnetization as the magnetic field was varied were thought at first to be peculiar to bismuth, but in time they were understood to be a fundamental property of all metals.

In a historical introduction, Shoenberg charts the course of the development of the de Haas-van Alphen effect, as it came to be called, from a curiosity to arguably the single most important experiment in solid state physics. We read of the insights of Landau on the origin of the effect, of the unexpected success of the nearly free electron model as crucial evidence in the development of pseudopotential theory, and of the subtle and fruitful interplay over the years between experiment and theory. The influence exerted on the course of solid state physics by studies of magnetic oscillations originated in large measure from their versatility and accuracy. Band theoretic methods, for example, could be fine-tuned and became more useful and reliable instruments in other fields. For more than half-a-century, in events from which the author has seldom been far removed, magnetic oscillations have been employed as a spectrometer for the investigation of electrons in metals. It is with these many aspects of the field that the book is principally concerned.

An objective early in the book is to expound the theory of magnetic oscillations, broadly along the lines first set out by Lifshitz and Kosevich in 1955, use being made of the now-familiar geometrical interpretation of electronic properties for the physical insight it provides. The theory is developed for both two- and threedimensional systems, with the more cumbersome mathematical results being helpfully placed in appendices. Given the historical development of the subject it is proper that the determination of Fermi surfaces (Fermiology), should have a prominent place. Here Shoenberg concentrates more on general principles, following this with a survey of what has been accomplished in a few selected metals. For a more encyclopaedic approach the reader is referred elsewhere.

In later chapters, attention is focused on more contemporary topics where, in to highlight areas where uncertainties remain, such as the effect of dislocations upon magnetic oscillations, nor those, such as the influence of many-body interactions, where even the general principles involved are still very much in question.

Although the study of magnetic oscillations has reached maturity as an established branch of solid state physics, this is remarkably the first book to be devoted to a complete exposition of the subject. Work on magnetic oscillations is still actively pursued and the author believes that this will continue for a long time yet. So too will his book remain the definitive text for research workers in this field.

Michael Springford is Professor of Experimental Physics at the University of Sussex. characteristic style, the author does not fail

\section{Cultural influence}

\section{Paula Brown Glick}

Ruth Benedict: Patterns of a Life.

By Judith Modell.

Chatto \& Windus/University of

Pennsylvania Press: 1984. Pp.355. Hbk

f15, \$30; pbk \$11.95.

Ruth BENEDIC.T (1887-1948) has occupied an important place in the history of American anthropology for the past 50 years, ever since the publication of Patterns of Culture in 1934. Judith Modell, the author of this biography, is herself an anthropologist and quite clearly feels a strong personal identification with her subject. Yet she does not attempt to evaluate Benedict's scholarship or contribution to anthropology.

The biographer is able to cite Ruth Benedict's published and unpublished writings - poems, notebooks, letters and an autobiographical fragment written in 1935 - in her examination of Benedict's childhood and youth. But now, over 30 years after Benedict's death, recollections culled from friends, relatives and students do not fully satisfy inquiry - many questions remain. From the characterization of Stanley Benedict, her husband, and of some close friends, the figures remain shadowy; here the reader must accept the limitations of the biographer's materials. Modell has attempted to discern the pattern of Benedict's life, and has certainly laid out the whole sweep of her person and her interests, as child and adult, in literature and anthropology. The influence of philosophical and religious thought upon Benedict is not fully examined, however; her feminism is muted. And a chapter on her anthropological work was evidently unduly influenced by Margaret Mead's books about Benedict, and seems uncritically repetitive.

Ruth Benedict was a student of Franz Boas of Columbia University, who has been called the "builder and architect of modern anthropology" and who built the Anthropology Department at Columbia University into a centre for anthropology, ethnography and folklore study. Ruth Benedict entered this realm in 1921, in her thirties, there finding a personal role, a purpose for her life and a new subject for writing. She visited American Indian settlements to record texts and cultural data from informants - the usual method of American anthropologists of the time and was Boas's closest assistant for 20 years, teaching and supervising students

\section{New in paperback}

A Feeling for the Organism: The Life and Work of Barbara McClintock by Evelyn Fox Keller. (W.H. Freeman, \$8.95, £7.95.) For review see Nature 304, 377; 1983.

- Darwin and His Critics by David L. Hull. (University of Chicago Press, \$15, £12.75.) For review see Nature 248, 285; 1974. 